\title{
"FOI COMO UMA VELA SE APAGANDO": INTERVENÇÃO COM TRABALHADORES BANCÁRIOS A PARTIR DE UM SUICÍDIO
}

'It was like a candle fading off': intervention with bank workers after a suicide

"C'était comme si une bougie que s'éteignait": intervention avec travaillieurs bancaires dans une situation de suicide

"Fue como una vela apagándose": intervención con trabajadores bancarios a partir de un suicid io

Carla Garcia Bottega ${ }^{1}$ Psicóloga, Doutora e Mestre em Psicologia Social e Institucional (UFRGS), Professora Adjunta em Saúde Coletiva Universidade Estadual do Rio Grande do Sul (UERGS) Psicóloga, Doutora e Mestre em Psicologia Social e Institucional (UFRGS), Professora na Universidade de Santa Cruz do Sul (Unisc)

Álvaro Crespo Merlo ${ }^{3}$ Médico do Trabalho, Professor Médico-Assistente do Hospital de Clínicas de Porto Alegre, Professor Titular da Universidade Federal do Rio Grande do Sul (UFRGS)

\section{Resumo}

Este artigo está baseado em uma intervenção em saúde e trabalho realizada com um grupo de ban cários que sofreu a perda de um colega que cometeu suicídio. Refere-se a um setor interno de um banco, localizado na cidade de Porto Alegre - Rio Grande do Sul. A demanda surgiu do Sindicato dos Bancários de Porto Alegre e Região em decorrência de um suicídio ocorrido no ambiente de trabalho no ano de 2012. A intervenção teve como objetivo inicial auxiliar os trabalhadores do setor na elaboração do trauma e do sofrimento provocado pela morte, buscando evitar sequelas psíquicas prolongadas e ao mesmo tempo de se aproximar das causas que levaram o trabalhador ao suicídio. Para tanto, foram realizadas entrevistas coletivas que forneceram subsídios para o acesso à organização do trabalho dos bancários deste setor. Para a execução do trabalho foram estudadas as questões que envolveram o suicídio no trabalho, observando fatores significativos do campo da atividade bancária, sendo este um dos setores que mais sofreu com as mudanças da reestruturação produtiva, especialmente nas últimas duas décadas. As entrevistas coletivas, realizadas no formato de grupo, foram coordenadas por integrantes do Laboratório de Psicodinâmica do Trabalho (LPdT/UFRGS) e composto pelos bancários dispostos a participarem voluntariamente dos encontros. Além disso, foi disponibilizado para tod os os trabalhadores do setor a aplicação do Self ReportQuestionary (SRQ-20). Este estudo evidenciou a necessidade de se propor uma forma de atenção as situações de adoecimento no trabalho bancário, bem como um trabalho efetivo nos processos de delimitações funcionais que muitas vezes não são bem trabalhadas e podem gerar outras formas de sofrimento/adoecimento muitas vezes invisibilizadas pelos novos modos de gestão. É importante também evidenciar a necessidade de se propor estratégias que visem prevenir o adoecimento no trabalho, resultado de indiscriminadas mudanças no setor bancário.

Palavras chave: Saúde mental e trabalho; Trabalho bancário; Suicídio.

\footnotetext{
${ }^{1}$ carlabott@terra.com.br

2karinevanessaperez@gmail.com

3 merlo@ufrgs.br
} 


\begin{abstract}
This article is based on an intervention in health and work carried out with a group of banke rs who suffered the loss of a colleague who committed suicide. Refers to an internal department of a bank, located in the city of Porto Alegre - Rio Grande do Sul. The demand came from the Bank Workers Union from Porto Alegre and Region after a suicide took place in the work place in 2012. The intervention had the initial objective of helping the workers from the department to elaborate on the trauma and suffering that came with the death, seeking to avoid prolonged psychic sequelae and at the same time to approach the causes that led the worker to suicide. Therefore, collective interviews were taken that provided subsidies that allowed to assess the work organization of the workers from that department. For this objective, issues that were related to the suicide at work were studied, observing important factors of the field of bank work, this being one of the fields that suffered the most with the changes of the productive restructuring, es pecially in the last two decades. The collective interviews, in a group format, were coordinated by members of the Work Psychodynamic Laboratory (LPdT/UFRGS) and composed by the bank workers willing to participate voluntarily of the meetings. Moreover, it was made available to all workers of the department the application of the Self Report Questionnaire (SRQ-20). This study made evident the need to propose a way to call for attention the situations that make the worker sick from bank work, as well as an effective work in the process of function delimitations that are often not well elaborated and can generate other forms of suffering/sickness many times made invisible by the new ways of management. It is also important to point out the need to propose strategies to prevent work sickness resulting from the indiscriminate changes in the banking sector.
\end{abstract}

Key-words: Mental health and work; Bank work; Suicide.

\title{
Résumé
}

Cet article traite d'une intervention en matière de santé au travail menée auprès d'un groupe de bancaires d'une succursale d'une banque, située dans la ville de Porto Alegre - Rio Grande do Sul. La demande provenait du Sindicat des travailleurs bancaires de Porto Alegre en 2012. Avec l'objectif initial d'aider les travailleurs du secteur à l'élaboration du traumatisme et des souffrances causées par la mort, afin d'éviter des séquelles psychiques prolongées et en même temps d'aborder les causes qui conduit le travailleur à se suicider, des entretiens collectifs ont été organisés qui prévoyaient la collect des informations pour permettre l'accès à l'organisation du travail des bancaires dans ce secteur. Pour l'exécution de l'étude, les problématiques liées au suicide au travail ont été étudiées en observant des facteurs significatifs dans le domaine de l'activité bancaire, celui-ci étant l'un des secteurs les plus touchés par les mutations productives des deux dernières décennies du siècle XXI. Les entretiens de groupe étaient coordonnés par des membres du Laboratoire de Psychodynamique du Travail (LPdT / UFRGS) et étaient composés de bancaires disposés à participer aux réunions. De plus, l'application du questionnaire d'auto-évaluation Self Report Questionary (SRQ-20) a été mise à la disposition de tous les travailleurs. Cette étude a mis en évidence la nécessité de proposer une attention aux situations de maladie dans le travail bancaire, ainsi qu'un travail efficace dans les processus de délimitations fonctionnelles qui souvent ne sont pas bien travaillées et peuvent générer d'autres formes de souffrance / maladie souvent invisibles dans les nouveaux modes de gestion. Il est également important de souligner la nécessité de proposer des stratégies de prévention de la maladie au travail, résultat de changements indiscriminés dans le secteur bancaire.

Mots-clés: Santé mentale; Travail bancaire; Suicide.

\section{Resumen}

Este artículo está bas ado en una intervención en salud y trabajo realizado con un grupo de bancarios que sufrió la pérdida de un compañero que cometió suicidio. La demanda surgió del Sindicato de los Bancarios de Porto Alegre y Región como consecuencia de un suicidio ocurrido en el ambiente de trabajo en el año 2012, en la ciudad de Porto Alegre - Rio Grande do Sul. La intervención tuvo como objetivo inicial auxiliar a los trabajadores del sector en la elaboración del trauma y del sufrimiento provocado por la muerte, buscando evitar secuelas psíquicas prolongadas y al mismo tiempo de aproximarse a las causas que llevaron al trabajador al suicidio. Para ello, se realizaron entrevistas colectivas que proporcionaron subsidios para el acceso a la organización del trabajo de los bancos de este sector. Para la ejecución del trabajo se estudiaron las cuestiones que involucraron el suicidio en el trabajo, observando factores significativos del campo de la actividad bancaria, siendo este uno de los sectores que más sufrió con los cambios de la reestructuración productiva, especialmente en las últimas dos décadas. Las entrevistas colectivas, realizadas en el formato de grupo, fueron coordinadas por integrantes del Laboratorio de Psicodinámica del Trabajo (LPdT / UFRGS) y compues to por los bancarios 
dispuestos a participar voluntariamente en los encuentros. Además, se puso a disposición para todos los trabajadores del sector la aplicación del Self Report Questionary (SRQ-20). Este estudio evidenció la necesidad de proponer una forma de atención a las situaciones de enfermedad en el trabajo bancario, así como un trabajo efectivo en los procesos de delimitaciones funcionales que muchas veces no están bien trabajadas y pueden generar otras formas de sufrimiento / enfermedad muchas veces invisibilizadas por los padres nuevos modos de gestión. Es importante también evidenciar la necesidad de proponer estrategias que busquen prevenir la enfermedad en el trabajo, resultado de indiscriminados cambios en el sectorbancario.

Palabras clave: Salud mental y trabajo; Trabajo bancario; Suicidio.

\section{Introdução}

A partir do suicídio de um trabalhador cometido no local de trabalho, em uma agência bancária de Porto Alegre/RS, o Laboratório de Psicodinâmica do Trabalho da Universidade Federal do Rio Grande do Sul-UFRGS recebe, do Sindicato dos Bancários, a demanda para uma intervenção neste contexto. A ideia era compreender as causas que levaram o bancário ao suicídio no próprio local de trabalho; auxiliar os trabalhadores do setor na elaboração do trauma e do sofrimento provocado pelo acontecimento, buscando evitar sequelas psíquicas prolongadas; e identificar alternativas que poderiam auxiliar na prevenção de agravos e na promoção da saúde desses trabalhadores. Estas ações buscaram proporcionar um espaço de fala e escuta para esses trabalhadores que poderiam sentir-se mobilizados pelo acontecimento, prevenindo assim possíveis reflexos psicopatológicos na vida daqueles que estavam ligados de algum modo ao trabalhador que se suicidou.

Com estes objetivos foram realizadas entrevistas coletivas, no formato de grupo, composto pelos colegas dispostos a participarem voluntariamente dos encontros; entrevistas com dois familiares, além de dois colegas que tinham proximidade com o bancário que cometeu suicídio. Também foi realizada a aplicação do Self Report Questionary (SRQ-20), disponibilizado para todos os trabalhadores do setor. Esse instrumento teve a função de levantar possíveis transtornos mentais e que poderiam ser agravados com a situação ocorrida.

Neste artigo apresentamos a intervenção com o coletivo de trabalhadores, focando nas entrevistas coletivas e nas respostas do SRQ-20. Além disso, serão apresentadas algumas considerações levantadas a partir das entrevistas individuais que buscaram compreender as motivações para o suicídio do bancário. Com isso conseguimos pensar nas questões referentes ao trabalho do bancário no contexto atual, e também perceber os indicativos de prazer/ saúde/ adoecimento/ sofrimento no trabalho desta equipe.

\section{Suicídio no trabalho}

Houve um grande avanço nos últimos anos no desenvolvimento do campo da saúde mental do trabalhador, em especial, a partir da compreensão proposta pela Psicodinâmica do Trabalho (Dejours, 1992, 2004). Esta proposta analisa a interrelação entre saúde mental e o trabalho e enfatiza a centralidade do trabalho na produção da saúde e da doença.

$\mathrm{O}$ trabalho tem uma função essencial na vida dos indivíduos. Ocupa um lugar central e organizador do cotidiano dos seres humanos. Por ter esta função significativa na vida, o trabalho pode ser tanto produtor de sentido, realização e prazer, contribuindo ativamente na construção da identidade do sujeito trabalhador, como também ser fonte de angústia, desesperança, sentimento de inutilidade e sofrimento, tendo, assim, um papel desestruturante da personalidade 
deste trabalhador que sofre e, por vezes, adoece física e psiquicamente a partir da relação com sua atividade laboral. Em alguns casos, todo este quadro de desestruturação psíquica e adoecimento pode levar ao suicídio.

Conforme Barreto e Venco (2011), o suicídio decorrente do vivido no trabalho denuncia um ambiente onde a violência se faz presente de diferentes maneiras e é percebida por meio da competitividade exacerbada, constantes pressões, sistemas de humilhações, ameaças e agressões (que muitas vezes são incorporadas pela gestão com estratégias de estímulo à produtividade e gerenciamento), individualismo, sentimento de solidão, ausência de companheirismo, medo e sofrimento.

Para Werlang e Oliveira (2006), o comportamento suicida expõe uma vivência e uma experiência psíquica que se articula com o sentimento de incapacidade do indivíduo encontrar alternativas para suportar ou superar uma determinada situação que lhe causa uma dor psicológica extrema. Desse modo, matar-se é a maneira encontrada pela pessoa para "dar conta" do drama que vem passando e que tem origem em necessidades psicológicas frustradas, que a própria pessoa julga como fundamentais e indispensáveis para a continuidade da vida.

O comportamento suicida em si não pode ser considerado uma entidade nosológica, mas uma manifestação patológica subjacente à determinantes múltiplos. Para Cassorla (1991) o suicídio pode ser considerado um evento culminante de uma série de fatores que vão se somando ao longo do tempo na vida de um sujeito que podem envolver situações ambientais, culturais, psicológicas, biológicas entre outras. O que é visto como "causa" geralmente se refere ao evento final destes acontecimentos. Barreto e Venco (2011, p.230) concordam com esta ideia e nos diz que
O suicídio, [...] resulta de múltiplos e distintos fatores, $\mathrm{o}$ que lhe confere uma multiplicidade discursiva, tornando-o de alguma forma um conceito polissêmico e quiçá, por isso, seja compreendido ao longo da história e até nossos dias como uma violência auto infligida e auto imposta, o que expressa a auto eliminação, autodestruição, auto assassinato e auto homicídio.

Mesmo com o aumento considerável das taxas de suicídio entre executivos, incluindo os trabalhadores do setor bancário (Santos, 2009), seja no Brasil, seja no exterior, há uma prática de silenciamento quanto a tentativa de se fazer $o$ nexo com $o$ trabalho. Aparentemente a relação entre suicídio e trabalho não existe, o que é uma ideia superficial, sustentada por teorias que buscam apenas focar a história pessoal dos indivíduos, ignorando a importância e centralidade do trabalho no contexto contemporâneo. $\mathrm{O}$ ato de excluir o mundo do trabalho das análises que focam o suicídio faz com que não se criem novas possibilidades de investigação e, a partir disso, limita-se a compreensão do ato em si, ignorando as novas expressões de dor e sofrimento que tem sido impostas pelo atual contexto do mundo do trabalho, regido pelo sistema capitalista onde as relações se mostram, inúmeras vezes, destrutivas (Barreto e Venco, 2011).

Os novos modelos de gestão, adotados por grande parte das empresas e até mesmo instituições públicas, favorecem a intensificação dos sentimentos de insegurança, desesperança, medos e auto exigências, impondo aos trabalhadores um nível mais elevado de sujeição diante de práticas gerenciais que exploram e violentam. As consequências destas mudanças, que ocorrem em nome do lucro desenfreado e da produtividade a qualquer 
preço, causam impactos na vida e na saúde dos trabalhadores, alterando valores, onde a ética muitas vezes é deixada de lado, desfazendo vínculos afetivos, contribuindo para o aumento da individualidade e da solidão (Barreto e Venco, 2011).

Santos (2009) desenvolveu uma pesquisa sobre o suicídio na área bancária, onde entrevistou familiares de um trabalhador que cometeu suicídio e outros que indicavam ter ideação suicida e tentativas, em que pôde observar que todos os casos pesquisados relacionavam o suicídio (tentativas e ideação) ao sofrimento vivenciado no trabalho. Assim, o contexto laboral passou a tornar-se não apenas fator coadjuvante, mas sim ocupar um papel central nas motivações relacionadas ao ato de acabar com a própria vida. $\mathrm{O}$ autor afirma ainda que as experiências negativas relacionadas à organização do trabalho foi um dos principais elementos que favoreceram a tomada de decisão dos pesquisados em idealizar, tentar ou consumar o ato suicida.

O sofrimento psíquico produzido pelas novas organizações do trabalho constitui diferentes formas de adoecimento onde o surgimento de patologias e os atos de suicídio é o final desse processo. Mesmo com avanços na área da saúde ainda encontramos dificuldades na caracterização da vinculação entre os quadros clínicos e o trabalho, tal como apontado por Seligmann-Silva (1995, p. 289):

Não existe um consenso que tenha permitido uma classificação dos distúrbios psíquicos vinculados ao trabalho, existe uma concordância da importância etiológica do trabalho, mas não a respeito do modo como se exerce a conexão trabalho/psiquismo de forma suficiente a permitir um quadro teórico. Os distintos modelos teóricos vêm trazendo dificuldades para a clínica e prevenção.

As consequências desta nova situação atingiram os servidores no seu estado de saúde, na sua capacidade de trabalho e na sua valorização funcional, tendo repercussões, inclusive, na aposentadoria. A própria instituição é afetada na medida em que ela vai sendo fragilizada pelas consequências da sobrecarga de tarefas sobre os servidores que continuam a trabalhar, levando a perda de trabalhadores experientes e, provavelmente, ao aumento dos gastos com saúde e folha de pagamento.

Dessa maneira, este trabalho busca apresentar uma intervenção feita com um coletivo de trabalhadores que sofreu a perda de um colega que cometeu suicídio. Para isso, é importante estudar a questão do suicídio no trabalho, para que o acolhimento aos colegas seja feito de forma ética,observando fatores significativos do campo do trabalho bancário, que foi um dos setores do mundo do trabalho contemporâneo que mais sofreu com as mudanças da reestruturação produtiva, iniciada em torno de 20 anos atrás.

\section{Procedimentos metodológicos}

$\mathrm{O}$ procedimento metodológico deve estar em consonância com o problema estudado, assim, foram utilizados os métodos de interpretação da Psicodinâmica do Trabalho, proposta por Dejours (1992, 2004), composto por entrevistas coletivas e individuais. Além disso um instrumento quantitativo, o Self-Reporting Questionnaire, SRQ-20 foi aplicado com o intuito de realizar um levantamento a respeito da existência de transtornos mentais menores.

A Psicodinâmica do Trabalho (PdT) utiliza um método que une intervenção à pesquisa, (Dejours, 2004) intitulada como Clínica do Trabalho. A 
Clínica do Trabalho desenvolve o campo da saúde mental e trabalho, intervindo em situações concretas. Busca a compreensão dos processos psíquicos envolvidos e a formulação de teoria e metodologia, num deslocamento e retorno constantes ao campo de trabalho.

O SRQ-20 é um instrumento utilizado para rastreamento psiquiátrico, sendo indicado pela Organização Mundial de Saúde (OMS) para uso de apoio diagnóstico principalmente nos serviços de atenção básica. Tem sido utilizado na detecção para transtornos mentais nãopsicóticos, sempre como complemento ao processo diagnóstico com entrevistas e avaliação em saúde mental (Gonçalves, Stein e Kapczinski, 2008; Santos, Araújo e Oliveira, 2009).

Contém, na versão brasileira, 20 questões, sendo que as respostas são tipo sim/não, podendo ser aplicado ou auto respondido. Cada resposta sim, é considerada 1 (um) ponto no valor total, sendo relacionado o valor final para 0 (nenhuma probabilidade) até 20 (extrema probabilidade) em relação à possibilidade de ocorrência de transtorno mental. $\mathrm{O}$ ponto de corte utilizado tem sido o de 7/8 respostas positivas (Gonçalves, Stein e Kapczinski, 2008). As 20 questões estão distribuídas em 4 grupos de sintomas para análise: Humor depressivo-ansioso (4 questões), Sintomas somáticos (6), Decréscimo de energia vital (6) e Pensamentos depressivos (4) (Santos, Araújo e Oliveira, 2009).

As entrevistas coletivas foram realizadas no formato de grupo, coordenado por integrantes do Laboratório (um médico do trabalho e duas psicólogas). Os entrevistados foram trabalhadores dispostos a participarem voluntariamente dos encontros. Além disso, foi disponibilizado para todos os bancários do setor a aplicação do Self Report Questionary (SRQ-20), mesmo aqueles que não participaram do grupo. Estas duas propostas, entrevistas e SRQ-20, foram úteis para que as pessoas pudessem pensar sobre o trabalho e elaborar o ocorrido, acessando assim os sentimentos referentes ao trabalhar e a perda sofrida com a morte do colega.

A entrevista privilegia a visão sobre o sofrimento e adoecimento em relação ao trabalho, e o que pode ser feito para seu enfrentamento. As questões dizem respeito ao cotidiano de trabalho, aos fatores pessoais e organizacionais, sem objetivar especificamente as características individuais e história de vida. De acordo com Mendes (2007, p. 69),

[...] define-se a entrevista como uma técnica de coletar dados, centrada na relação pesquisadores-pesquisados e na fala-escuta-fala dos conteúdos manifestos e latentes, sobre a organização do trabalho, as vivências de prazer-sofrimento, as mediações, e os processos de subjetivação e de saúdeadoecimento.

Foram realizadas reuniões com representantes do Sindicato, desde o esclarecimento da demanda, apresentação de projeto e, durante o processo do estudo, para informação da execução e discussão. Estes momentos foram importantes para que pudéssemos conhecer um pouco mais sobre o local de trabalho, o histórico do banco e do setor, interligando àquilo que os trabalhadores falavam durante os encontros. A intenção foi reunir informações para o entendimento do caso de forma mais detalhada e conseguir auxiliar o grupo de trabalhadores após a situação de estresse vivenciada por eles.

O primeiro contato com o grupo de trabalhadores foi feito em conjunto com o Sindicato e representantes do Laboratório, um médico e uma psicóloga. Neste momento, além da explanação do Sindicato, foi feita proposta das entrevistas coletivas e explicitação dos objetivos do estudo. Neste encontro, estavam presentes 25 trabalhadores que falaram sobre $\mathrm{o}$ 
suicídio, perguntaram sobre o método de trabalho e o seguimento do estudo. Ficou acordado um novo encontro nas dependências do Sindicato, com dia e hora marcados, com a presença dos interessados.

No primeiro encontro para as entrevistas coletivas foram retomadas as combinações relativas ao andamento do grupo, tais como participação e registros, buscando esclarecer os objetivos e as questões de ordem ética para o desenvolvimento do trabalho, como o sigilo e arquivo das informações e do material produzido.

As reuniões se realizaram no sindicato, local combinado previamente com os participantes, com duração de aproximadamente uma hora e meia. Foram realizados dois encontros, com a participação de dez e cinco bancários, respectivamente. Os encontros foram gravados com o consentimento prévio dos participantes.

O foco dos encontros foi sempre o comentário verbal feito pelos trabalhadores, pois é a partir das falas que se conhece o trabalho realizado e os efeitos causados no trabalhador. Além disso, vale ressaltar que o que interessa, segundo a metodologia da PdT, é a expressão coletiva proporcionada por este espaço de fala (Mendes, 1995).

A análise do material foi feita a partir da fundamentação teórica da Psicodinâmica do Trabalho, sempre levando em conta as particularidades da organização do trabalho e a subjetividade dos trabalhadores envolvidos.

Por sua vez, foram feitas duas entrevistas individuais com familiares, e duas com colegas que objetivaram conhecer um pouco mais do "universo" do trabalho a partir da visão dos trabalhadores. Essas entrevistas foram conduzidas por duas profissionais da equipe, após combinação prévia, sendo que tiveram duração de uma hora e trinta minutos a duas horas. Os participantes foram informados sobre os objetivos do estudo e puderam optar ou não por sua participação livremente, sendo realizadas com pessoas próximas ao trabalhador que cometeu o suicídio.

\section{Resultados}

Resultados da aplicação do instrumento SRQ-20

O instrumento SRQ-20 foi entregue a todos os trabalhadores do setor, em envelope fechado, sem identificação, sendo que 33 questionários foram devolvidos respondidos. $\mathrm{O}$ setor investigado conta com um número de 45 trabalhadores. $\mathrm{Na}$ ocasião existiam pessoas de férias e Licença Médica.

É importante salientar que dos 33 questionários respondidos 8 não tiveram nenhuma alternativa afirmativa marcada, onde todas foram respondidas com a resposta "não", negando a presença dos sintomas questionados. Além disso, dentre os 33 participantes, uma pessoa indicou a resposta sim para a pergunta 17 (Tem tido ideias de acabar com a vida?), o que pode ser entendido que há ideação suicida entre um dos trabalhadores do setor investigado. Tal fato deve ser cuidadosamente observado no sentido de se promover alguma forma de prevenção ao adoecimento mental e seus agravamentos, o que pode incluir o desejo de suicidar-se. Os resultados obtidos são apresentados a partir de gráficos, seguidos de comentário interpretativo dos mesmos, esclarecendo assim a sua representação.

O gráfico 1 apresenta um comparativo entre as respostas "sim" e "não" fornecidas pelos bancários que participaram da aplicação deste instrumento. De acordo com orientações referentes a avaliação dos resultados, é importante observar os valores correspondentes ao "sim", pois é a partir deste que podemos indicar a possibilidade da presença de transtorno psíquicos 
menores (Gonçalves, Stein e Kapczinsk, 2008).

Conforme pode ser verificado no gráfico abaixo, a questão que recebeu mais respostas afirmativas foi a número 6, recebendo um total de 17 marcações e diz respeito ao sentimento de estar nervoso(a), tenso(a) ou preocupado(a). A questão número 9 , que se refere a presença do sentimento de tristeza nos últimos dias, recebeu 14 marcações. Já as questões 1 e 19 receberam 11 marcações e dizem respeito a ter dores de cabeça com frequência e cansar-se facilmente. As questões $1,6,9$, e 19 foram as que receberam o maior número de respostas afirmativas e por isso é importante salienta-las.

Gráfico 1: Comparativo entre as respostas "sim" e "não" das 20 questões do SRQ-20

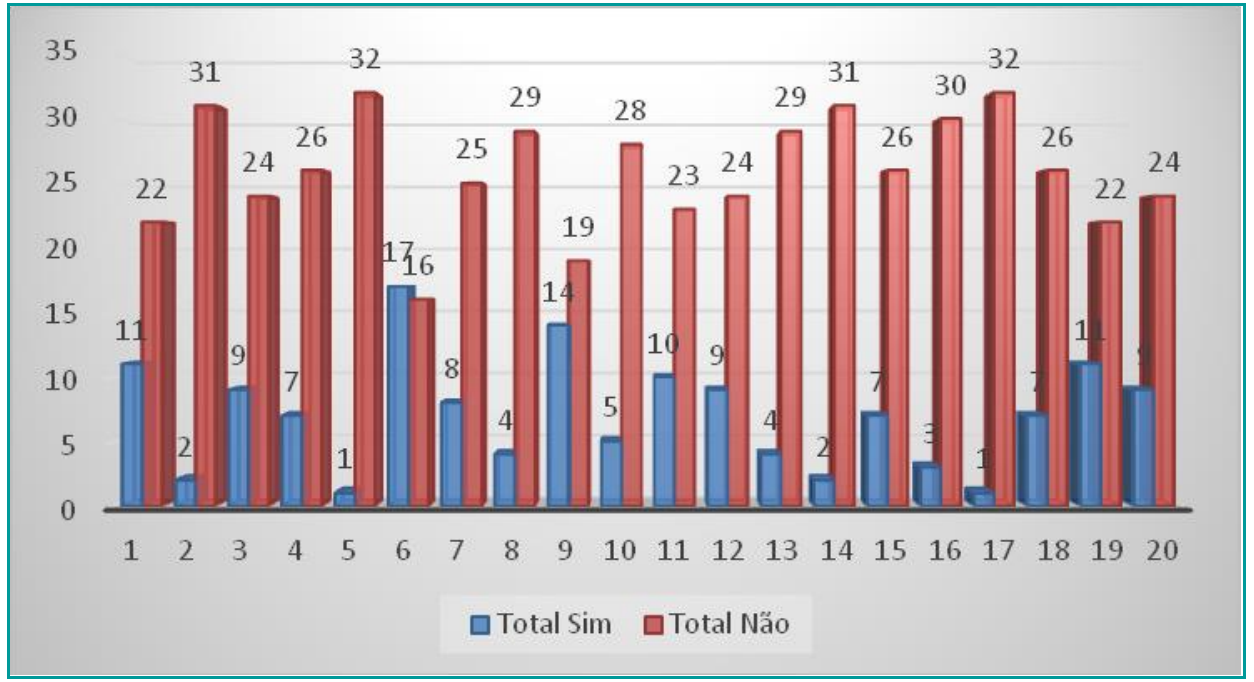

Fonte: Respostas dos participantes ao SRQ 20.

No gráfico 2 são apresentadas as análises referentes as respostas afirmativas, onde 8 pessoas, equivalente a $24 \%$ dos respondentes, assinalaram 8 ou mais alternativas, com a indicação de presença de sintomas. Dessa forma, pode-se supor que estas pessoas possam apresentar indícios de Transtornos Mentais Menores, pois responderam afirmativamente a 8 perguntas ou mais do SRQ-20.

Gráfico 2: Respostas afirmativas

\section{Respostas}

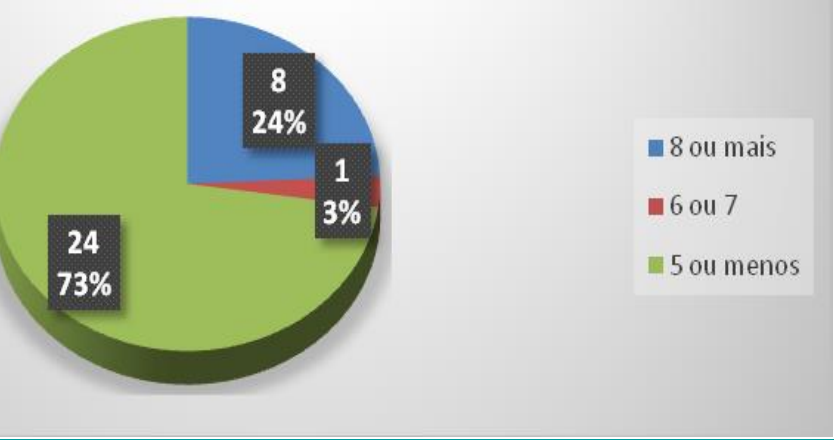

Fonte: Respostas dos participantes ao SRQ 20. 
Com relação aos sintomas, o gráfico 3 apresenta a divisão proposta pelo instrumento

(Self-Reporting Questionnaire), que busca analisar o humor depressivo-ansioso, sintomas somáticos, decréscimo de energia vital e pensamentos depressivos. De acordo com o gráfico abaixo, os sintomas que mais prevalecem são aqueles referentes ao decréscimo de energia vital. Tal categoria sintomática envolve as seguintes questões: "Encontra dificuldades para realizar com satisfação suas atividades diárias? Tem dificuldades para tomar decisões? Tem dificuldades no serviço (seu trabalho é penoso, causa sofrimento)? Sente-se cansado(a) o tempo todo? Tem sensações desagradáveis no estômago?".

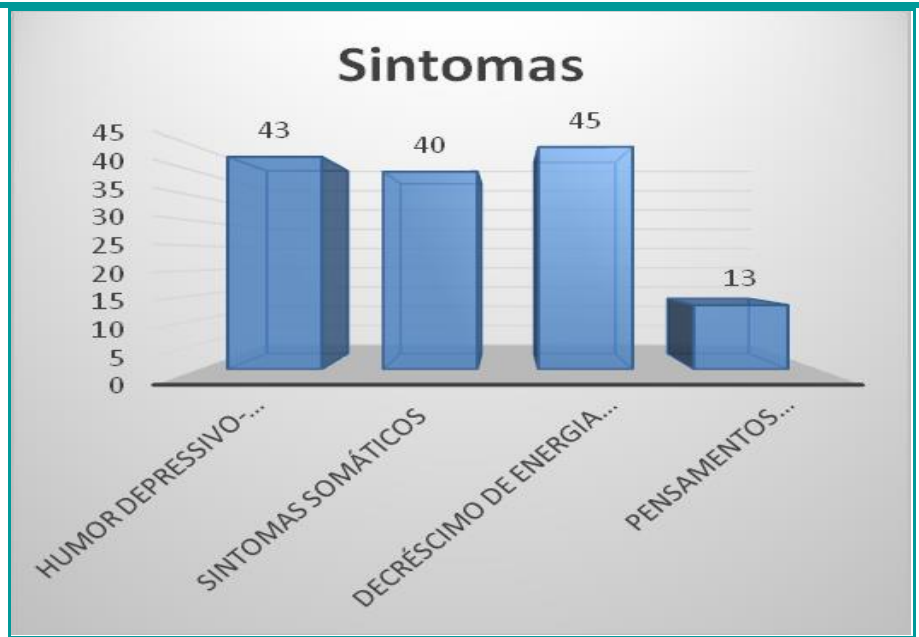

Fonte: Respostas dos participantes ao SRQ 20.

O gráfico 4 se refere à descrição dos sintomas que dizem respeito ao decréscimo de energia vital que recebeu a maior parte das marcações afirmativas (45\%). Neste quesito, a questão número 19 recebeu 11 marcações, o que corresponde $24 \%$ a se cansar-se facilmente enquanto a questão 11 que questiona se o participante tem encontrado dificuldades para realizar com satisfação suas atividades diárias recebeu $22 \%$ das marcações, ou seja 10 participantes assinalaram "sim" para esta questão.

Gráfico 4: Sintoma Decréscimo de Energia Vital

\section{Decréscimo de Energia Vital}

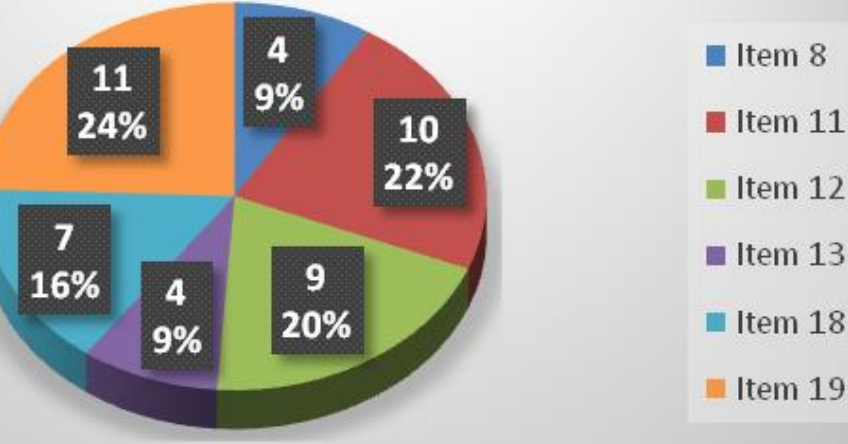

Fonte: Respostas dos participantes ao SRQ 20. 
O gráfico 5 apresenta as porcentagens referentes ao sintoma humor depressivo-ansioso que recebeu um total de $43 \%$. Como pode ser observado, a questão que recebeu mais marcações e que se enquadra neste sintoma foi a número 6 (Sente-se nervoso(a), tenso(a) ou preocupado(a)?) o que representou um total de 39\%. Já o item 10 recebeu $33 \%$ das marcações o que significa que 14 pessoas responderam afirmativamente a pergunta "Tem chorado mais que do costume?".

Gráfico 5: Sintoma Humor Depressivo-Ansioso

\section{Humor Depressivo-Ansioso}

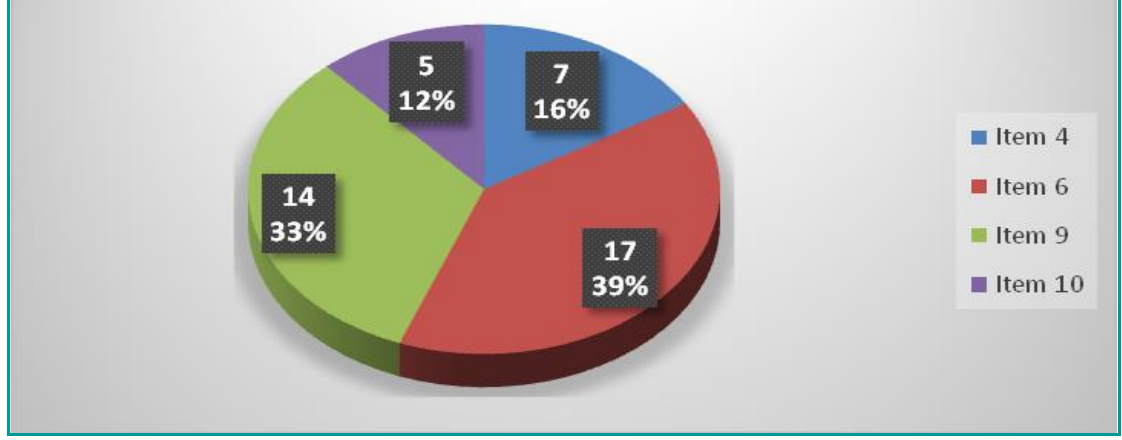

Fonte: Respostas dos participantes ao SRQ 20.

No gráfico 6, condizente aos sintomas somáticos, que teve como percentual $40 \%$, pode ser observado que o item 1 foi o que recebeu o maior número de marcações positivas, o que representou 27\% (11 pessoas assinalaram esta questão) e diz respeito a pergunta "Você tem dores de cabeça frequentes?". A questão número 20 "Têm sensações desagradáveis no estômago?" foi assinalada positivamente por 9 pessoas, o que gerou uma porcentagem de $23 \%$.

Gráfico 6: Sintomas Somáticos

\section{Sintomas Somáticos}

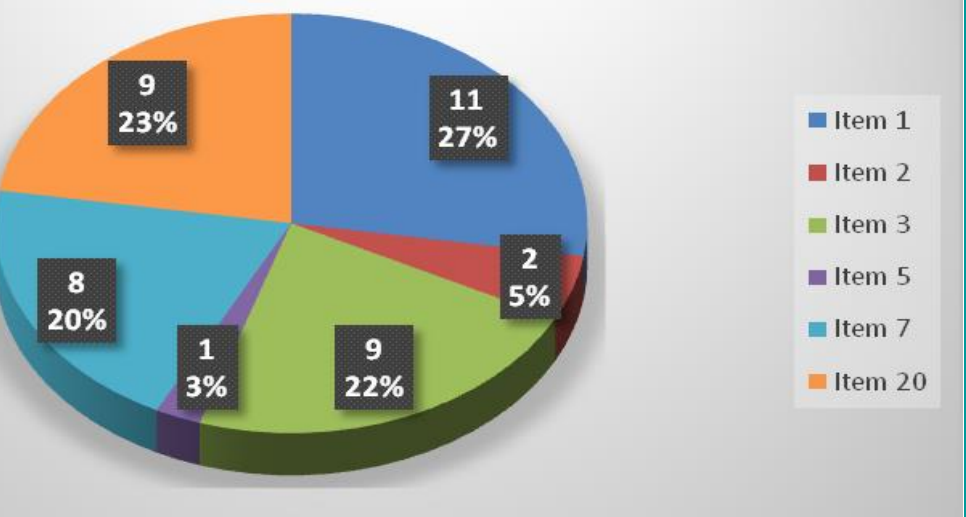

Fonte: Respostas dos participantes ao SRQ 20.

O gráfico 7 se refere aos sintomas que caracterizam os pensamentos depressivose recebeu um total de $13 \%$ das marcações afirmativas. $54 \%$ dos participantes responderam afirmativamente que "Tem perdido o interesse pelas coisas" 
representando 7 das marcações. Já 3 pessoas responderam sim para a pergunta "Sente-se uma pessoa inútil, sem préstimo?" o que gerou um percentual de $23 \%$ em relação a esta categoria.

Gráfico 7: Sintomas Pensamentos Depressivos

\section{Pensamentos Depressivos}

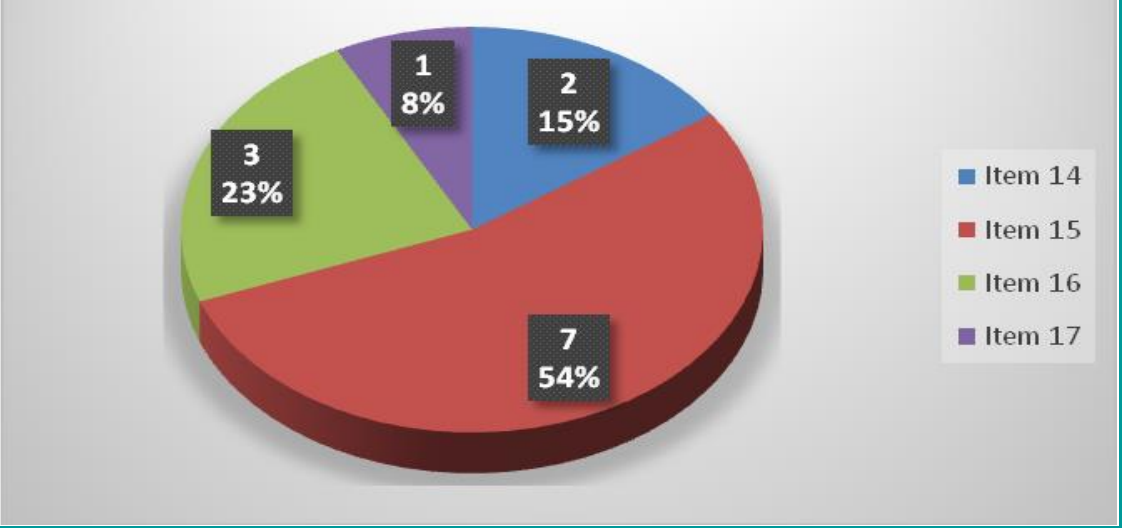

Fonte: Respostas dos participantes ao SRQ 20.

Neste estudo, o SRQ-20 pode dar uma noção prévia de como se encontra a saúde dos trabalhadores e como isto deve influenciar nas medidas promotoras de saúde mental no ambiente de trabalho. Mesmo sendo um instrumento quantitativo deve-se ter um olhar cuidadoso para as respostas fornecidas. É o caso da resposta afirmativa dada a questão 17 (Tem tido idéias de acabar com a vida?), que mesmo sendo uma única pessoa que tenha marcado "sim", alguma ação no sentido de prevenir esta ideação deve ser pensada, ainda mais em um setor onde um suicídio já foi cometido no local de trabalho.

\section{Resultados das entrevistas}

Com o objetivo inicial de auxiliar os trabalhadores do setor na elaboração do trauma e do sofrimento provocado pelo suicídio do colega, buscando evitar sequelas psíquicas prolongadas, iniciamos a abordagem de entrevistas coletivas com os interessados. Segundo Dejours e Bègue (2010), na investigação clínica é necessário continuar em busca do significado do suicídio no trabalho. Além disso, as entrevistas coletivas forneceram subsídios para que fosse possível aos colegas a remontagem da história do trabalhador falecido, momento importante onde todos puderam expressar suas percepções a respeito do que poderia estar acontecendo na vida desta pessoa, tanto no trabalho quanto em questões pessoais.

Ocorre que logo após o suicídio, a instituição bancária havia disponibilizado aos colegas de setor a possibilidade de apoio psicológico e/ou médico e alguns trabalhadores já tinham sido acolhidos após o evento e conversado sobre o acontecimento. Portanto, as entrevistas coletivas não foram a primeira abordagem pós-suicídio para alguns dos participantes. Segundo um dos funcionários:

A INSTITUIÇÃO está enxergando o custo humano, mas não está sabendo o que fazer com isso e comofazer...

Nas entrevistas coletivas os participantes fizeram relatos sobre $\mathrm{o}$ histórico do dia do suicídio, bem como seu entendimento sobre o processo vivido 
pelo colega. Puderam também elaborar ou reelaborar a situação de culpa vivenciada neste momento, por acreditarem que poderiam ter agido de forma diferenciada e isso "magicamente" poderia ter modificado a situação. Como por exemplo, ter dado um abraço no colega ou conversado mais naquele dia.

Será que eu não podia ter conversado mais com ele ou ter dado um abraço naquele dia?

Mas de uma forma geral o que foi trazido nas falas foi a tristeza pelo colega "ter desistido de viver". Conforme nos apontam Dejours e Bègue (2010, p. 15), a importância não está no número de suicídios encontrado no local de trabalho, pois 'Um único suicídio em uma empresa constitui, de facto, um problema que afeta toda a comunidade de trabalho, uma vez que sua ocorrência reflete uma profunda degradação do conjunto do tecido humano e social do trabalho".

Entre os participantes do grupo havia, tanto colegas que tinham anos de convivência com o trabalhador em questão, quanto outros que não tinham muita proximidade, pelo pouco tempo de convívio, ou pela execução da atividade. Mesmo assim, todos falaram de suas considerações sobre o acontecimento, bem como o que lhes suscitou posteriormente.

É difícil... Logo que aconteceu pensava muito no assunto, sentia necessidade de contar sobre o fato ocorrido para as pessoas próximas.

Me fez pensar também como a gente é meio invisivel na empresa, mas é assim, em toda empresa é assim.

Foram trazidas rememorações de suicídio vividas com pessoas próximas ou familiares; medo de outra situação semelhante; outras mortes que já acorreram no ambiente bancário, inclusive outros suicídios; a preocupação com colegas mais instrospectivos que, de alguma forma, se mobilizaram com a situação ocorrida, mas tinham dificuldades para expressar: "Não querem falar para não sofrer novamente..."; e também a preocupação com quem encontrou o bancário morto, que no caso foi um estagiário.

Em nossa abordagem, no acolhimento das falas não foram encontradas situações que levassem à constatação de uma possível situação de Transtorno de Estresse Pós-Traumático ou outra forma de comprometimento psíquico importante. Ocorre que a elaboração da situação vivenciada já se encontrava em curso, inclusive com a possibilidade de mudança do setor para outro local, o que já estava sendo pensado há algum tempo e, com a situação de suicídio, foi agilizada.

Acho que a gente merece sair de lá... a energia que ficou não é boa...

$\mathrm{O}$ andar onde ocorreu o suicídio, que era um local de pouca circulação, logo após o ocorrido foi desativado por completo.

Segundo os relatos, o colega já vivia há alguns anos uma situação de adoecimento e "desinvestimento" do trabalho, o que não era comum para a imagem que a equipe tinha dele.

\section{Ele estava sem paciência...}

Havia um esvaziamento da questão do trabalho na vida dele.

Havia sido, inclusive, participante ativo do sindicato e muito mobilizado pelas lutas da categoria bancários e resolveu deixar a atividade sindical por vontade própria. 
O "Fulano" era muito inteligente e muito crítico... olhei o facebook dele e ele colocava muitas coisas que demonstravam o quanto ele era crítico e que ele não se encaixava...

Sim, ele era um crítico disso, era preocupado com as pessoas...

Mesmo assim, seguia indo ao sindicato frequentemente, inclusive no dia de sua morte. Uma indicação evidente deste desinvestimento, segundo os relatos dos colegas, é que já não enviava mais mensagens "provocativas sobre política" como fazia anteriormente. Há uma tendência para as pessoas de uma forma geral, bem como para as empresas na busca de que o "gesto suicidário" seja explicado pelo temperamento depressivo ou psicopatológico do suicida, ou a conflitos afetivos da esfera privada (Dejours e Bègue, 2010), o que pode ou não se configurar na realidade.

Segundo relatos dos colegas, o trabalho no banco sempre foi algo de extrema importância para o trabalhador falecido, onde este buscava desenvolver sua atividade com empenho e dedicação, acreditando no significado que este produzia, tanto para ele, como para seu meio social. Entretanto, nos últimos anos, o processo de restruturação ocorrido na empresa, buscando de forma desenfreada aumentar a produtividade, através do estímulo pelo atingimento de metas e pela perda de benefícios e garantias sociais da classe bancária, parecem ter sido fatores relevantes no processo de desilusão e descrença pessoal na instituição bancária sentida pelo trabalhador que se suicidou.

Não cumpria mais com as suas tarefas. Antigamente ele fazia além, sempre buscava mais atividades para se ocupar.
A este quadro acrescentou-se, nos últimos anos, um adoecimento, inicialmente físico, e depois, segundo relatos, um possível "transtorno depressivo". Isso o levou a um afastamento por licença saúde e um não retorno para a atividade anterior (que seria de maior importância no setor). A sua atividade de trabalho sofreu delimitação de função e diminuição de carga horária. Pode-se pensar que a mudança na execução das atividades, proposta pela empresa a partir da situação de adoecimento, tenha sido um fator importante, que tenha contribuído para uma retirada gradual de energia no trabalho, na medida em que este passou a não mais receber $o$ devido reconhecimento pelo seu trabalho atual e, principalmente, pela sua contribuição histórica e sua dedicação anterior.

Sabe-se que o sofrimento psíquico produzido pelo trabalho costuma ser mais importante naqueles trabalhadores comprometidos com as suas tarefas, o que parece se relacionar com este caso. De acordo com um dos colegas, o modelo de gestão no setor tem sido uma das maiores dificuldades para a realização do trabalho; os critérios das ações não são claros, e os mais críticos e/ou com mais tempo de trabalho são os mais visados para mudarem suas atitudes e até mesmo saírem do setor, as relações pessoais se sobrepõe às relações de trabalho, trazendo muitas dificuldades.

Conforme nos apontam Dejours e Bègue (2010, p.41), a dinâmica do reconhecimento visa à transformação do sofrimento em prazer. "Ora a identidade é a armadura da saúde mental. De sorte que, no momento em que um trabalhador se beneficia de reconhecimento, ele pode tirar proveito no registro da construção de sua saúde mental". Mas o contrário, traz um grande risco para o equilibrio psíquico e para a identidade do trabalhador, o que parece ter sido o caso deste trabalhador bancário. 
Foi referido que ele não conseguia mais cumprir com as suas tarefas, enquanto que antigamente ele fazia além, sempre buscando mais atividades para se ocupar. Segundo os relatos,

Foi como uma vela se apagando...

Ele foi definhando na frente de todo mundo...

Ele foi se encolhendo, não sorria mais [...] não tinha mais energia...

Não foi surpresa o que aconteceu pelo andamento do que estava acontecendo com ele.

Não era uma pessoa de falar muito da vida pessoal, nem conversar muito, mas relatos indicam que seria mais aberto ao diálogo no trabalho do que em casa, e que estaria passando por uma longa situação de crise no casamento.

Foi informado que realizou uma cirurgia no ombro e que esta patologia não foi reconhecida pela empresa como produzida pelo trabalho, o que, segundo os relatos dos próprios colegas e familiares, provocou-lhe uma grande decepção e um forte ressentimento com a empresa. Apesar disso, fazia fisioterapia regularmente.

De acordo com Dejours e Bègue (2010, p. 41), “O reconhecimento, é importante salientar, não é relativo à pessoa do trabalhador". O que o trabalhador espera é o reconhecimento pelo trabalho bem feito, pela sua realização, o retorno pelo esforço realizado, que transforma o sofrimento da realização em prazer. E o autor diz ainda, (Dejours e Bègue, 2010, p.41) 'De reconhecimento em reconhecimento, o indivíduo pode perceber o fortalecimento de sua identidade, sua maior consistência, sua consolidação".
Pelo aparente quadro depressivo alguns colegas insistiram com ele na busca de algum tipo de apoio psicoterápico, mas, ao que consta, ele nunca chegou a realizar. Também foi percebido que houve um emagrecimento aparente nos últimos 18 meses, apesar de alimentar-se bem. Inclusive, relatos de mudança na cor da pele. Era fumante, e há indicação de ter parado ou pelo menos ter diminuído o uso do cigarro. Os colegas suspeitaram de resultados negativos na realização de exames de saúde no último período, mas não conseguimos nenhuma comprovação, nem junto aos colegas, nem junto aos familiares. Não foram encontrados exames, medicações ou prescrições médicas em sua casa ou no local de trabalho.

Apesar disto, alguns colegas levantaram a suspeita de que ele tenha recebido um possível diagnóstico de uma doença grave. De acordo com Dejours e Bègue (2010, p. 31), "Encontrar comumente elementos como esses no histórico post mortem não significa que sejam sempre a causa do suicídio". Sabemos que o dentro e o fora do trabalho é um entendimento equivocado, na medida em que o sujeito tem apenas uma estrutura psicológica e que o espaço do trabalho avança na vida doméstica, assim como o contrário. Não é incomum que situações vividas no trabalho, sejam levadas para a vida particular, familiar e ali tragam dificuldades de relacionamento e adoecimento, entre outras, que demorem a se manifestar na situação de trabalho, ou sejam associadas à mesma.

Aparentemente, havia indicações de uma relação ambígua com a própria vida na última semana, pois ao mesmo tempo em que tinha desmarcado o atendimento da fisioterapia e encaminhamento de documentos no sindicato, estava fazendo planos com familiares para festividades que aconteceriam em breve. Nem os colegas, nem os familiares receberam nenhuma 
indicação de que ele estivesse com intenções de terminar com a própria vida.

Foi lembrado que o dia de sua morte foi o mesmo dia da morte da mãe e por isso pode ser que haja alguma relação entre os dois fatos, mas que, no nosso entender, indicam apenas o surgimento de mais um fator desencadeante e não uma causa em si.

\section{Considerações finais}

A não elucidação de uma situação de suicídio, seja no trabalho, seja fora dele, traz fortes sentimentos de ansiedade e o seu não-esclarecimento e/ou silenciamento pode trazer consequências negativas para os colegas de trabalho e à familia do trabalhador (Dejours e Bègue, 2010). Desta maneira, a investigação realizada buscou reunir o máximo de informações disponíveis sobre o caso, visando produzir uma resposta coerente.

Porém, nem sempre isso é possível. Seja pela complexidade dos múltiplos fatores envolvidos, internos e externos, seja pela ausência, em muitos casos, de informações objetivas.

Nosso entendimento é que um suicídio no ambiente de trabalho é sempre endereçado, pelo simples fato de ter ocorrido neste local e não em outro. A escolha do local para o ato deve ser analisada e entendida como fazendo parte do processo de planejamento anterior deste sujeito que, por alguma razão, opta pelo espaço de trabalho entre tantos outros. Por mais que não tenha deixado uma sinalização, uma carta ou alguma forma de esclarecimento para a familia ou colegas, este trabalhador estabeleceu uma relação com o local que naquele momento fazia sentido em sua história de vida. Evidentemente, não pode deixar de ser lembrado de que um suicídio no espaço doméstico deixaria este local "marcado" de forma permanente e, talvez, pudesse inviabilizar a permanência futura da familia. Porém, existem outros locais para a realização de um suicídio além do local de trabalho e do domicilio. Principalmente se o suicídio ocorre com tão poucos meios físicos, como foi este caso. Assim, pensamos que, levando em consideração o processo de reestruturação do trabalho promovido pela empresa, a história de compromisso que este trabalhador teve no passado com suas tarefas e com a própria militância sindical, não é possível descartar o papel do trabalho no desfecho do suicídio.

A história deste trabalhador apresenta situação real de adoecimento, com mudança de comportamento, bem como alterações físicas, mas há também presente uma alteração em sua relação com o trabalho e o exercício de suas atividades laborais. Nossa investigação e as informações levantadas foram suficientes para permitir suspeitar sobre a contribuição do trabalho neste caso, pois que sabemos que o trabalho opera como fator de extrema importância para a manutenção da saúde ou adoecimento de todos os trabalhadores. Reações defensivas são utilizadas para que o sujeito suporte a violência e conviva com um sistema de gestão do qual deseja ao mesmo tempo se livrar e, muitas vezes, o adoecimento e o afastamento do trabalho vai ser a única forma de continuar a existir como sujeito, objetiva e subjetivamente.

Consideramos que são necessárias estratégias que possam reconstituir $o$ viver-junto e formar as bases da cooperação, após um caso de suicídio no ambiente de trabalho. Ao final da intervenção, salientamos a importância de que estes trabalhadores possam ter um espaço de fala e escuta que possa ser um permanente elaborar e pensar sobre $o$ acontecido no cotidiano do trabalho, na medida em que os espaços coletivos na contemporaneidade estão cada vez mais esvaziados ou inexistentes.

Não se deve esquecer que a categoria dos bancários já tem documentado outros casos de suicídio em local de trabalho, seja em Porto Alegre, 
seja em outras cidades do país. E que este suicídio precisa ser levado muito a sério, na medida em que pode configurar-se como um "caso-sentinela". Em se tratando de suicídios em local de trabalho, não se deve raciocinar de forma epidemiológica tradicional. Basta um caso para que o alerta seja dado e sejam tomadas medidas de proteção e de prevenção à saúde dos outros trabalhadores daquele local.

Este estudo evidenciou a necessidade de se propor uma forma de atenção as situações de adoecimento no trabalho bancário, bem como um trabalho efetivo nos processos de delimitações funcionais que muitas vezes não são bem trabalhadas e podem gerar outras formas de sofrimento/adoecimento.

Compartilhamos o pensamento de Dejours e Bègue (2010, p.124), que evidenciam que apesar das dificuldades que se pode enfrentar em realizar uma intervenção em uma organização que teve uma situação ou situações de suicídios, a ação da busca pelo esclarecimento é poderosa, porque apresenta " $[\ldots]$ a vantagem de mostrar que a vontade de compreender pode prevalecer sobre a causalidade do destino."

Diante deste relato pode-se perceber, portanto, que uma intervenção no campo da saúde e trabalho em situações em que a fragilidade humana é evidenciada pode representar uma oportunidade de ressignificação do vivido. Além disso, desse modo, se oferece espaço para elaboração do sofrimento diante da perda e suas relações.

\section{Referências}

Barreto, M., Venco, S. Da Violência ao Suicídio no Trabalho. In: Barreto, M., Netto, N. B., Pereira, L.B. (Org.) (2011). Do assédio moral à morte de si: significados sociais do suicídio no trabalho.1 ed. São Paulo: Matsunaga.
Cassorla, R. M. S. Considerações sobre o suicídio. In: Cassorla, R. M. S (Org.) (1991). Do suicídio: estudos brasileiros (PP. 17-26). Campinas: Papirus.

Dejours, C.; Bègue, F. (2010). Suicídio e trabalho: o que fazer? Brasilia: Paralelo 15.

Dejours, C. In: Lancman, S.; Sznelwar, L.I. (2004). Christophe Dejours - Da Psicopatologia à Psicodinâmica do Trabalho. Rio de Janeiro: Ed. Fiocruz, Brasilia: Paralelo.

(1992). A loucura do trabalho: estudo de psicopatologia do trabalho. São Paulo: Cortez-Oboré.

Gonçalves, D. M.; Stein, A. T.; Kapczinski, F. (2008). Avaliação de desempenho do Self-Reporting Questionnaire como instrumento de rastreamento psiquiátrico: um estudo comparativo com o Structured Clinical Interview for DSM-IVTR.Cad. Saúde Pública, Rio de Janeiro, v. 24, n. 2, Feb. Disponível em:

$\leq$ http $/ /$ www.scielo.br/scielo.php?scri $\mathrm{pt}=$ sci arttext\&pid=S0102311X2008000200017\&lng=en\&nrm= iso>. Acesso em 12 nov. 2012

Mendes, A. M. (2007) Pesquisa em psicodinâmica: A clínica do trabalho. In: Mendes, Ana Magnólia. (Org.). Psicodinâmica do trabalho: Teoria, método, pesquisas. São Paulo: Casa do Psicólogo, v. 1.

Mendes, A. M. (1995) Aspectos psicodinâmicos da relação homemtrabalho: as contribuições de C. Dejours. Psicologia: Ciência e Profissão, Brasilia , v. 15, n. 1-3, p. 34-38. Disponível em http://www.scielo.br/scielo.php?script $=$ sci arttext\&pid=S1414- 
98931995000100009\&lng=en\&nrm=i

so Acesso fev. 2012.

Santos, M. A. F. (2009). Patologia da

Solidão: o suicídio de bancários no contexto da nova organização do trabalho. 239 f. Dissertação (Mestrado em Administração) Programa de Pós-Graduação em Administração, Universidade Federal de Brasîlia. Brasîlia.

Santos, K. O. B.; Araujo, T. M. de; Oliveira, N. F. de. (2009). Estrutura fatorial e consistência interna do SelfReporting Questionnaire (SRQ-20) em população urbana. Cad. Saúde Pública, Rio de Janeiro, v. 25, n. 1, Jan. Disponível em: http:/www.scielo.br/scielo.php?script $=$ sci_arttext\&pid=S0102311X2009000100023\&lng=en\&nrm= iso>. Acesso em 12 nov.2012

Seligmann-Silva, E. Psicopatologia e psicodinâmica no trabalho. (1995). In: Patologia do Trabalho (R. Mendes, ed.), pp. 287-310, Rio de Janeiro: Ed. Atheneu.

Werlang, B. S. G.; Oliveira, M. da S. Dor Psicológica e Suicídio: aproximações teóricas. In: Werlang, B. S. G.; Oliveira, M. da S. (Org). (2006). Temas em Psicologia Clínica. 1 ed. São Paulo: Casa do Psicólogo, 2006. 